\title{
Differential Diagnosis and Workup of Monocytosis: A Systematic Approach to a Common Hematologic Finding
}

\author{
Abhishek A. Mangaonkar ${ }^{1}$ (D) Aaron J. Tande ${ }^{2} \cdot$ Delamo I. Bekele $^{3}$ \\ Accepted: 23 February 2021 / Published online: 20 April 2021 \\ (C) The Author(s), under exclusive licence to Springer Science+Business Media, LLC, part of Springer Nature 2021
}

\begin{abstract}
Purpose of Review Monocytosis is a frequently encountered clinical condition that needs appropriate investigation due to a broad range of differential diagnoses. This review is meant to summarize the latest literature in the diagnostic testing and interpretation and offer a stepwise diagnostic approach for a patient presenting with monocytosis.

Recent Findings Basic studies have highlighted the phenotypic and functional heterogeneity in the monocyte compartment. Studies, both translational and clinical, have provided insights into why monocytosis occurs and how to distinguish the different etiologies. Flow cytometry studies have illustrated that monocyte repartitioning can distinguish chronic myelomonocytic leukemia, a prototypical neoplasm with monocytosis from other reactive or neoplastic causes.

Summary In summary, we provide an algorithmic approach to the diagnosis of a patient presenting with monocytosis and expect this document to serve as a reference guide for clinicians.
\end{abstract}

Keywords Monocytosis · Monocytes · Classical · Intermediate $\cdot$ Non-classical $\cdot$ Chronic Myelomonocytic Leukemia

\section{Introduction}

Monocytes and their tissue-specific mature counterparts, macrophages, are key components of the mononuclear phagocyte system involved in ingestion of microorganisms and foreign material in various tissues. They also regulate inflammatory and immune responses by interacting with lymphocytes and serve as antigenpresenting cells by differentiating into dendritic cells [1]. Upon response to activating signals such as chemokines and cytokines, activated monocytes adhere and migrate to the sites of infection or inflammation through diapedesis. In addition, monocytes have a

This article is part of the Topical Collection on Myelodysplastic Syndromes and MPN/MDS Overlap

Abhishek A. Mangaonkar

mangaonkar.abhishek@mayo.edu

1 Division of Hematology, Mayo Clinic, Rochester, MN, USA

2 Division of Infectious Diseases, Mayo Clinic, Rochester, MN, USA

3 Division of Rheumatology, Department of Medicine, Mayo Clinic, Rochester, MN, USA poorly defined interaction with the coagulation cascade (Fig. 1).

Based on expression of lipopolysaccharide co-receptor, $\mathrm{CD} 14$, and Fc $\gamma \mathrm{III}$ receptor, CD16, at least three functionally distinct populations of monocytes are known to exist in the body [2]. Classical monocytes (MO1, CD14 $4^{++}, \mathrm{CD} 16^{-}$) represent the largest subgroup involved in phagocytosis through the glycolytic and pentose phosphate pathway [2]. Conversely, the non-classical (MO3, CD14 ${ }^{\mathrm{dim}}, \mathrm{CD}_{1} 6^{+}$) monocyte fraction is associated with oxidative phosphorylation pathway and protein metabolism, and the intermediate $\left(\mathrm{MO} 2, \mathrm{CD} 14^{+}, \mathrm{CD} 16^{+}\right)$subset is associated with antigen presentation to other immune cells [2,3]. These associations with distinct pathways suggest diverse physiological roles for monocytes in healthy individuals. Recently, many groups have shown existence of transitional and intermediary subsets of monocytes with diverse functions, reflecting significant functional heterogeneity in the monocyte compartment $[4,5$, $6 \cdot \bullet]$.

Several disease states are associated with monocytosis with diverse clinical presentations. This review is focused on how to accurately identify the underlying etiology in adult patients presenting with an elevated monocyte count. Readers are also referred to another comprehensive review on the topic [7•]. 


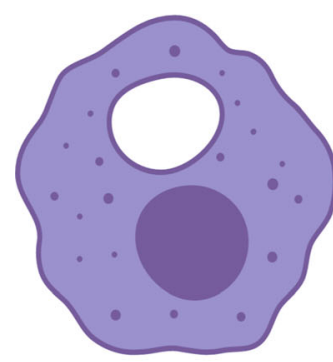

Macrophage-associated phagocytosis

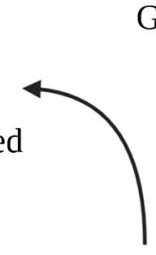

GM-CSF receptor

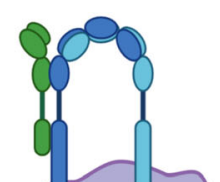

LPS receptor

(CD14)

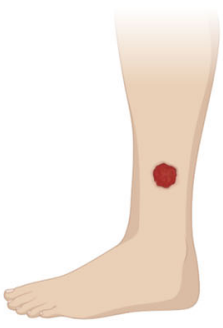

Wound healing

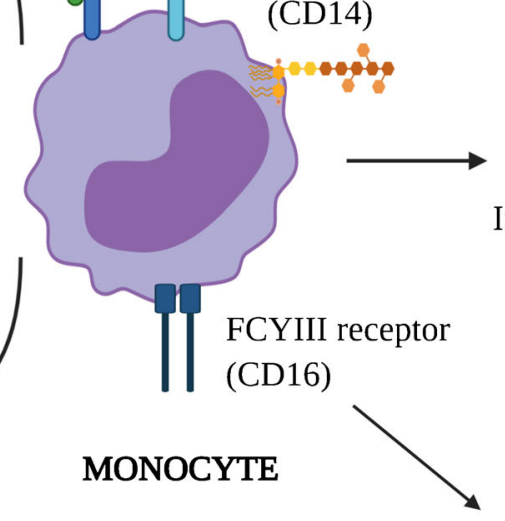

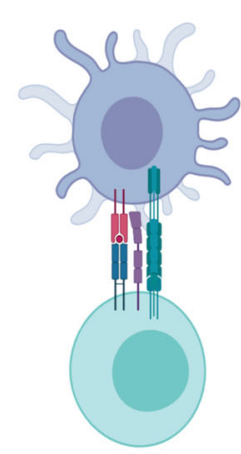

Dendritic cell-mediated antigen presentation

Fig. 1 The diverse functions of monocytes in humans. Monocytes are characterized by expression of several cell surface receptors. This figure highlights some of those receptors and the key monocyte-associated functions such as macrophage-associated phagocytosis, dendritic cell-

\section{Monocytosis Definition}

The normal absolute monocyte count ranges in adults ranges in between $0.2-0.8 \times 10^{9} / \mathrm{L}$, with values varying significantly with age and sex. Under normal physiology conditions, monocyte counts are usually slightly higher in males; however total white blood cell count and other WBC types such as lymphocytes and granulocytes are not significantly different [8]. Further, monocytes are more sensitive to inflammatory stimuli in men than women likely secondary to sex hormone differences $[8,9]$. Racial differences are only minimal, with some studies showing no significant differences [10], while others indicating a slightly lower absolute monocyte counts in Blacks and Asians compared to Caucasians [11, 12]. The World Health Organization defines persistent monocytosis as an absolute monocyte count $\geq 1 \times 10^{9} / \mathrm{L}$ with monocytes accounting for $\geq 10 \%$ of leukocytes persisting for $\geq 3$ months [13].

\section{Differential Diagnoses of Monocytosis}

The various causes of monocytosis can be divided into two broad categories: reactive or clonal (Table 1). mediated antigen presentation, wound healing, interactions with coagulation cascade, and regulation of inflammatory responses (created with BioRender.com)

\section{Reactive Causes}

Transient causes: Monocytosis can been seen in a patient with recovering bone marrow after cytotoxic chemotherapy [14]. Stressful events such as splenectomy [15], myocardial infarction [16], and exercise [17] can also result in monocytosis and are often transient and reversible [7॰]. However, monocytosis is also a frequent occurrence in acutely ill patients, with one prospective study observing this finding in over a quarter of patients seen in a Swiss emergency department [18]. In this study, patients presenting with infections or respiratory illness were significantly more likely to present with monocytosis than other illnesses. Certain acute bacterial infections, such as leptospirosis [19] or listeriosis [20], can be classically associated with monocytosis. Recently, SARS-CoV-2-associated COVID-19 disease has been associated with increase in inflammatory HLA-DR ${ }^{++} \mathrm{CD} 11 \mathrm{c}^{++} \mathrm{CD} 14+$ monocytes in mild cases, and dysfunctional HLA-DR ${ }^{\operatorname{dim}} \mathrm{CD} 163^{++}$and HLA-DR ${ }^{\mathrm{dim}} \mathrm{S} 100 \mathrm{~A}^{++}$monocytes, disappearance of nonclassical CD $14^{\mathrm{dim}} \mathrm{CD} 16^{+}$monocytes in severe cases, further highlighting the important role of monocytes in regulating systemic inflammatory responses $[21,22]$. However, the finding of monocytosis in the acute setting is neither sensitive nor 
Table 1 Table showing the differential diagnosis of monocytosis

\begin{tabular}{ll}
\hline Reactive & Clonal \\
\hline Transient & Acute neoplasms \\
Bone marrow recovery & Acute monocytic or myelomonocytic leukemia \\
Exercise-induced & Dendritic cell leukemia \\
Acute infections & Chronic neoplasms \\
Splenectomy & Chronic myelomonocytic leukemia \\
Medication-induced & Juvenile myelomonocytic leukemia \\
Myocardial infarction & Myeloid neoplasms with PDGFRB rearrangement \\
Stress-induced & (Can mimic CMML)* \\
& Myeloid neoplasms with PDGFRA rearrangement* \\
Persistent & Myeloid neoplasms with FGFR1 rearrangement* \\
Chronic infections & Myeloid neoplasms with PCM1-JAK2 fusion* \\
Rheumatologic conditions & Chronic myeloid leukemia \\
Medication-induced & Myeloproliferative neoplasms with monocytosis: \\
& a. Essential thrombocythemia \\
& b. Polycythemia vera \\
& c. Primary myelofibrosis \\
Systemic mastocytosis \\
B and T cell malignancies \\
Solid tumors \\
\end{tabular}

*Associated with concomitant eosinophilia specific for any particular etiology. The most appropriate and cost-effective diagnostic evaluation in the acute setting is to repeat monocyte count once the acute inflammatory response has resolved.

Persistent causes: A diverse group of subacute or chronic infections have been associated with monocytosis. These include syphilis [23], brucellosis [24], malaria [25], tuberculosis [26], visceral leishmaniasis [27], and rickettsial infection[28]. While these case reports and case series are intriguing, they should be interpreted with caution. Rather than suggesting a unique laboratory finding in these disparate infections, they more likely reflect a non-specific finding among a constellation of other clinical features.

Monocytosis can also be seen in chronic autoinflammatory disorders, primarily divided into two major categories: (1) granulomatous disorders: sarcoidosis and inflammatory bowel disease (ulcerative colitis) and (2) systemic rheumatologic disorders including rheumatoid arthritis (RA), systemic lupus erythematous (SLE), and immune-mediated thrombocytopenia. Vasculitis (polyarteritis nodosa) and myositis [7•,29], SLE and RA commonly present with leukopenia, including lymphopenia and neutropenia.

Medications can also result in monocytosis. While neutrophillia is more commonly seen with corticosteroid therapy, monocytosis has been reported [30]. Drugs such as ziprasidone [31], granulocyte colony stimulating factor (GCSF, [32]), radiation therapy [33], and anti-thymocyte globulin [34] have all been associated with monocytosis [7•].
When evaluating for causes of a persistent reactive monocytosis, the most important approach begins with a thorough history of illness and physical examination, including an appropriate infectious diseases exposure history which includes assessment of tuberculosis risk, international travel history, and risk of zoonotic infections. Recurrent fevers, night sweats, and/ or weight loss are supportive but are not specific for an occult infection since chronic inflammatory disorders and neoplastic causes can also manifest with these symptoms. Additional symptoms suggestive of a chronic systemic illness should warrant a review of systems covering features of rheumatic disorders. If clinically indicated, further testing should include autoantibodies and imaging studies. Given the rarity of monocytosis as the presenting finding of rheumatic disease, attention may need to be focused on the differential diagnosis including infections and clonal etiologies. Additional/associated symptoms, temporal trends of the leukocyte and monocyte counts along with pharmacotherapy should be explored.

\section{Clonal Causes}

Based on acuity of presentation, clonal causes can be divided acute and chronic neoplasms (Table 1). The acute neoplasms include acute myeloid leukemia (AML) and dendritic cell leukemia. Historically, the French-American-British (FAB) classification categorized monocytic acute leukemia into two subtypes: acute myelomonocytic leukemia (M4) and acute 
monoblastic/monocytic leukemia (M5) [35]. In the 2017 World Health Organization classification, monocytic leukemias have been classified under AML, not otherwise specified (NOS) [13]. Chronic myeloid neoplasms with monocytosis include chronic myelomonocytic leukemia (CMML) and its pediatric counterpart also known as juvenile myelomonocytic leukemia (JMML), myeloproliferative neoplasms with monocytosis, myeloid neoplasms with PDGFRB (can mimic CMML), PDGFRA or FGFR1 rearrangement or the provisional PCM1-JAK2 fusion, and systemic mastocytosis.

CMML is the prototypical myeloid neoplasm with monocytosis defined by the presence of monocytosis $(\geq 1 \times$ $10^{9} / \mathrm{L}$ ) with monocytes accounting for $\geq 10 \%$ of leukocytes in the absence of WHO-criteria for BCR/ABL1-positive chronic myeloid leukemia and myeloproliferative neoplasms, and absence of PDGFRA, PDGFB, and FGFR1 rearrangements or PCM1-JAK2 fusions, blast count $<20 \%$ of cells in both bone marrow and peripheral blood, and presence of dysplasia in one or more lineages (absence of dysplasia does not exclude the diagnosis of CMML if there is evidence of clonal molecular or cytogenetic changes, and monocytosis is persistent $(\geq$ 3 months) [13, 36, 37]. Morphologically, it may be difficult to distinguish blasts from promonocytes or monoblasts and is counted together clinically when calculating total blast percentage in both peripheral blood and bone marrow assessment. Biologically, the combination of somatic variants in epigenetic (TET2, ASXL1, IDH1/2, or DNMT3A) and splicing factor genes (SRSF2, ZRSR2, or $S F 3 B 1)$ or signaling pathway genes $(R A S, J A K 2$ or $C B L)$ results in monocytosis [38, 39]. The precise mechanism of monocytosis is unclear but may be at least partly explained by hypersensitivity to granulocytemacrophage-colony stimulating factor (GM-CSF) signaling [40], which is also a relevant therapeutic target in CMML [41]. CMML is often associated by variants in the aforementioned group of genes; however it is also genetically heterogenous, which indicates the existence of other mechanisms of monocytosis. On the contrary, JMML is more genomically homogenous and associated with RAS pathway genes (PTPN11, KRAS, NRAS, NF1, or CBL) but also characterized by GM-CSF hypersensitivity of myeloid progenitors [42]. Monocytosis can be seen in other chronic myeloid neoplasms such as myeloproliferative neoplasms (MPN), either at diagnosis or during the course of the disease. The presence of MPN features in the bone marrow or MPN-associated variants (JAK2/CALR/MPL) supports the diagnosis of MPN with monocytosis rather than CMML [13]. A minority of patients with myelodysplastic syndromes can also present with monocytosis (not otherwise meeting criteria for CMML); however they are likely at an early stage of evolution toward CMML [43] or can be classified as oligomonocytic CMML which is considered a pre-CMML condition due to similar clinico-pathologic and molecular features $[44,45 \bullet \cdot]$.
Some independent studies have assessed monocyte repartitioning as a diagnostic tool in CMML. The original study by Selimoglu-Buet D et al. established that the expansion of the classical fraction of monocytes (> 94\%) has been shown to be associated with a sensitivity of $90.6 \%$ and specificity of $95.1 \%$ in diagnosing chronic myelomonocytic leukemia [46••]. Subsequent studies reaffirmed this finding $[47,48]$. One study noted that decreased percentage of the MO3 fraction $(<1.13 \%$ in peripheral blood, $<2.42 \%$ in bone marrow) has a better sensitivity and specificity when compared with MO1 fraction expansion (> 94\%) for the diagnosis of CMML [49]. However, there are some studies that advise caution when using this approach [50]. In the presence of coexisting rheumatologic or other reactive conditions, there is a preferential expansion of $\mathrm{MO} 2$ fraction, and therefore the aforementioned diagnostic cut-offs for the MO1 or MO3 fraction may not be as sensitive or specific for the diagnosis of CMML $[50,51]$. This could be partly related to the transcriptomic heterogeneity in the monocyte compartment, especially in the MO2 compartment [6••], indicating the existence of additional functionally distinct subtypes beyond the three fractions. Although we recommend the use of this assay in distinguishing CMML from other neoplastic causes of monocytosis, caution should be exercise in patients with co-existing rheumatologic conditions or disorders. Recent techniques in cell phenotyping such as time of flight mass cytometry (CуTOF) can be potentially used to help further refine the diagnostic accuracy of monocyte repartitioning in CMML, by employing markers other than CD14 and CD16 such as CD36, CCR2, HLA-D4 and CD11c [50, $52 \cdot, 53 \bullet \cdot, 54]$.

\section{Approach to Evaluation of a Patient with Monocytosis}

When approaching a patient with monocytosis, we recommend assessing chronicity and pattern of monocytosis, along with a comprehensive history and physical exam. Morphology of the monocytes should be confirmed on a peripheral smear to assess dysplasia. Monocytosis plus dysplasia or additional complete blood count abnormalities such as anemia, thrombocytopenia, eosinophilia, or basophilia, or clinical indicators of malignancy such as splenomegaly, bone pain, or weight loss among others indicate a clonal etiology and in these cases a bone marrow aspirate/ core biopsy assessment should be performed. In addition to standard morphological and cytogenetic/molecular assessment, dual staining with alpha-naphthyl butyrate-esterase and naphthol AS-D chloroacetate esterase may help in distinguishing the monocytic component and also in 
distinguishing monocytes from monoblasts and/or promonocytes (Figs. 2 and 3) [55]. Dual staining with both the aforementioned dyes indicates the existence of dysmyelopoietic cells, whereas pure monocytic cells stain positive only for alpha-naphthyl butyrate-esterase [55]. In the absence of dysplasia and isolated monocytosis, a repeat complete blood count in 3 months can be considered. Resolution of monocytosis at that time-point indicates a reactive etiology. However, if the monocytosis is persistent, then a comprehensive clinical assessment for reactive causes should be undertaken, sometimes in coordination with other sub-specialist experts such as rheumatology or infectious diseases. Monocyte compartment flow cytometry assessment can be considered. However, if there are concomitant rheumatic conditions, then we recommend proceeding straight to bone marrow evaluation due to the aforementioned limitations of monocyte repartioning. The expansion of CD16+ fraction of monocytes often indicates a non-neoplastic etiology; however it should be considered that clonal disorders such as CMML and MDS have an established association with rheumatic conditions $[56,57]$. In other words, both reactive and

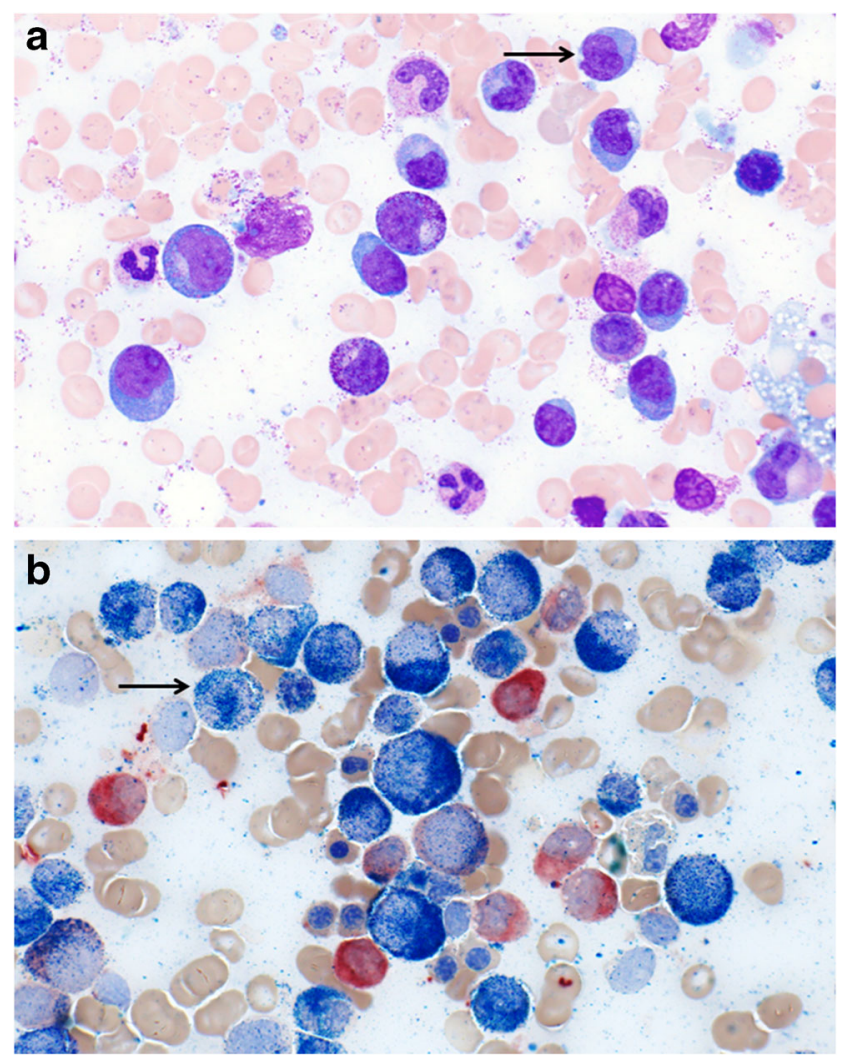

Fig. 2 Bone marrow aspirate evaluation of a patient with chronic myelomonocytic leukemia. a Shows hematoxylin and eosin staining at $\times 1000$ magnification. Arrow points to monocytes. b Shows dual staining of CMML bone marrow aspirate with alpha-naphthyl butyrate-esterase and naphthol AS-D chloroacetate esterase indicating increased monocytic cells (staining only alpha-naphthyl butyrate-esterase) for shown at $\times 1000$ magnification (Courtesy: Kaaren K Reichard, MD)

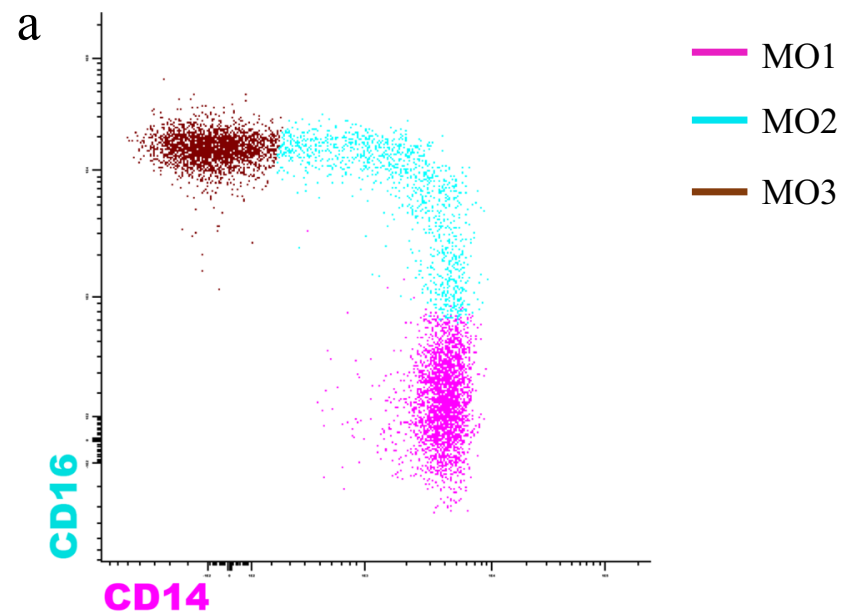

$\mathrm{b}$
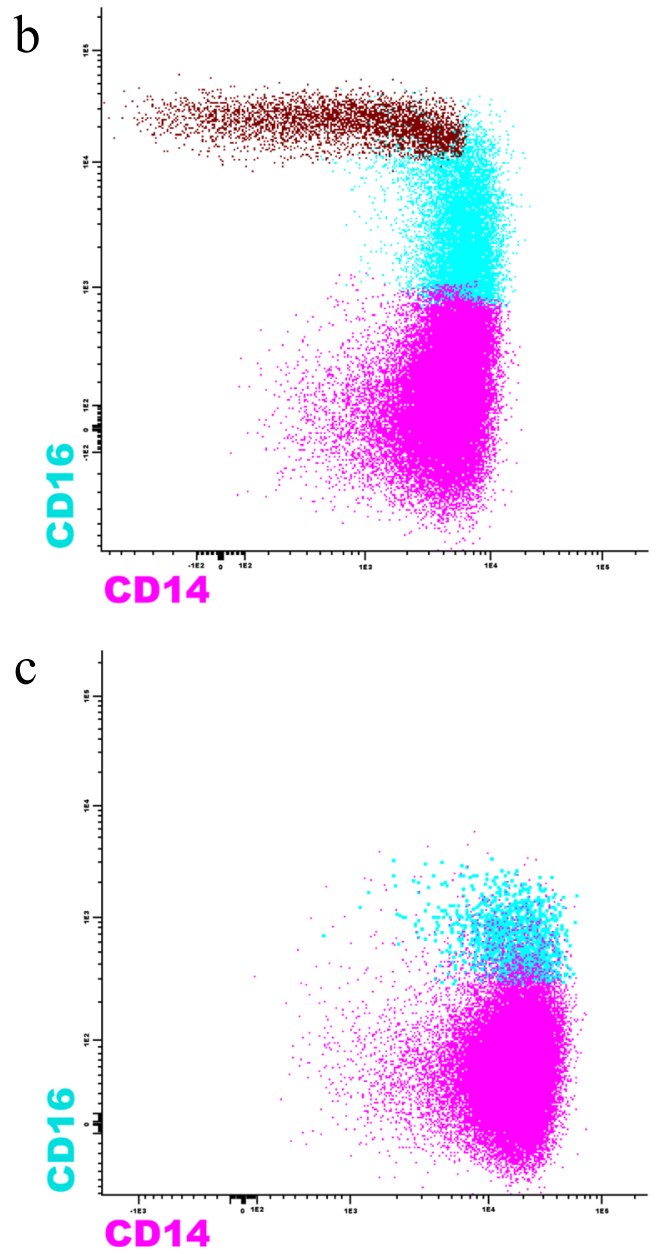

Fig. 3 Figure showing flow cytometry-based monocyte repartioning patterns in normal individuals, reactive monocytosis and chronic myelomonocytic leukemia (CMML). In CMML, there is a preferential expansion of the classical (> 94\%, MO1, CD14++, CD16-) monocyte fraction as opposed to intermediate $\left(\mathrm{MO} 2, \mathrm{CD} 14^{+}, \mathrm{CD}^{+} 6^{+}\right)$and nonclassical fraction $\left(\mathrm{MO} 3, \mathrm{CD} 14^{\mathrm{dim}}, \mathrm{CD} 16^{+}\right)$(Courtesy: Michael M. Timm)

clonal causes could exist in the same individual and appropriate judgment should be employed in each clinical situation (Fig. 4). 
Fig. 4 Figure outlining a stepwise approach for a patient presenting with monocytosis. Abbreviations: $\mathrm{CBC}=$ complete blood count; $\mathrm{CMML}=$ chronic myelomonocytic leukemia

Monocytosis

\section{Confirm morphology on peripheral blood smear}

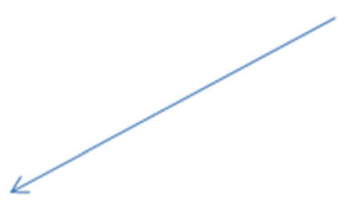

No dysplasia and isolated monocytosis

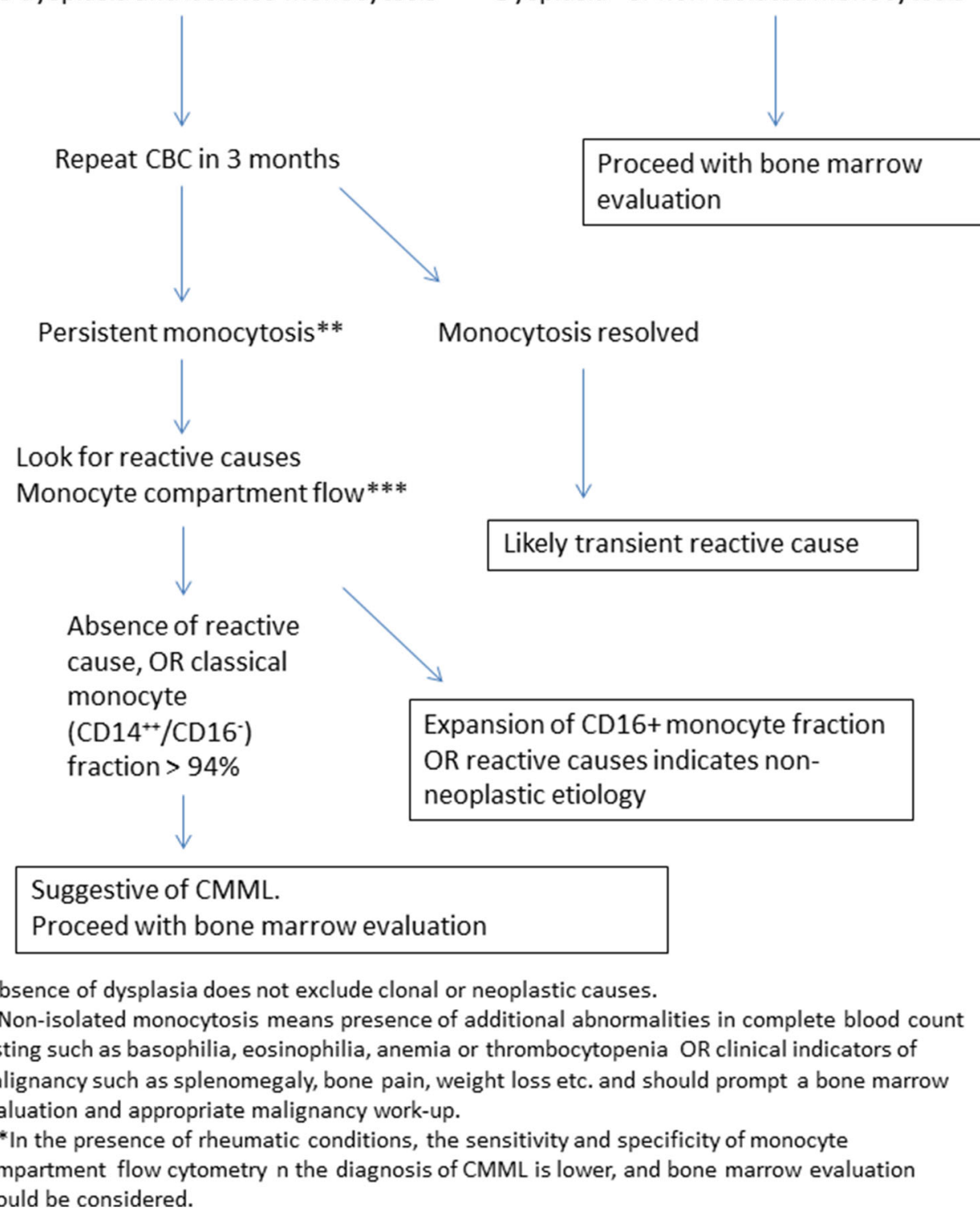

\section{Conclusion}

In summary, monocytosis is a common hematologic finding with a broad range of etiologic possibilities. We provide an algorithmic approach for investigating monocytosis and highlight the recent advances in phenotypic characterization of monocytes. Future areas of research should involve characterization of monocyte compartment heterogeneity, both in normal and disease-states through novel technologies such as 
CyTOF. This would not only increase the precision of monocyte repartioning as a diagnostic tool but also offer novel insights into disease biology.

Acknowledgements Authors would like to acknowledge Kaaren K. Reichard, MD, for the bone marrow aspirate (Fig. 2) images and Michael M. Timm for the flow cytometry (Fig. 3) images.

\section{Declarations}

Conflict of Interest The authors declare no competing interest.

Human and Animal Rights and Informed Consent This article does not contain any studies with human or animal subjects performed by any of the authors.

\section{References}

Papers of particular interest, published recently, have been highlighted as:

- Of importance

-• Of major importance

1. Kenneth Kaushansky MAL, Prchal JT, Levi MM, Press OW, Burns LJ, Caligiuri MA. Williams Hematology. 9th ed; 2016. p. 1045100.

2. Schmidl C, Renner K, Peter K, Eder R, Lassmann T, Balwierz PJ, et al. Transcription and enhancer profiling in human monocyte subsets. Blood. 2014;123(17):e90-9. https://doi.org/10.1182/ blood-2013-02-484188.

3. Ziegler-Heitbrock L, Hofer TP. Toward a refined definition of monocyte subsets. Front Immunol. 2013;4:23. https://doi.org/10. 3389/fimmu.2013.00023.

4. Teh YC, Ding JL, Ng LG, Chong SZ. Capturing the fantastic voyage of monocytes through time and space. Front Immunol. 2019;10:834. https://doi.org/10.3389/fimmu.2019.00834.

5. Chong SZ, Evrard M, Devi S, Chen J, Lim JY, See P, et al. CXCR4 identifies transitional bone marrow premonocytes that replenish the mature monocyte pool for peripheral responses. J Exp Med. 2016;213(11):2293-314. https://doi.org/10.1084/jem.20160800.

6.• Villani AC, Satija R, Reynolds G, Sarkizova S, Shekhar K, Fletcher $\mathrm{J}$, et al. Single-cell RNA-seq reveals new types of human blood dendritic cells, monocytes, and progenitors. Science. 2017;356(6335). https://doi.org/10.1126/science.aah4573. This is an important paper highlighting the heterogeneity in human monocyte compartment.

7. Lynch DT, Hall J, Foucar K. How I investigate monocytosis. Int J Lab Hematol. 2018;40(2):107-14. https://doi.org/10.1111/ijlh. 12776. This is a comprehensive review on how to investigate monocytosis.

8. Bouman A, Schipper M, Heineman MJ, Faas MM. Gender difference in the non-specific and specific immune response in humans. Am J Reprod Immunol. 2004;52(1):19-26. https://doi.org/10.1111/ j.1600-0897.2004.00177.x.

9. Saxena S, Wong ET. Heterogeneity of common hematologic parameters among racial, ethnic, and gender subgroups. Arch Pathol Lab Med. 1990;114(7):715-9.

10. Tollerud DJ, Clark JW, Brown LM, Neuland CY, Pankiw-Trost LK, Blattner WA, et al. The influence of age, race, and gender on peripheral blood mononuclear-cell subsets in healthy nonsmokers. $\mathrm{J}$ Clin Immunol. 1989;9(3):214-22. https://doi.org/10.1007/ bf00916817.

11. Freedman DS, Gates L, Flanders WD, Van Assendelft OW, Barboriak JJ, Joesoef MR, et al. Black/white differences in leukocyte subpopulations in men. Int J Epidemiol. 1997;26(4):757-64. https://doi.org/10.1093/ije/26.4.757.

12. Lim E, Miyamura J, Chen JJ. Racial/ethnic-specific reference intervals for common laboratory tests: a comparison among Asians, Blacks, Hispanics, and White. Hawaii J Med Public Health. 2015;74(9):302-10.

13. Swerdlow SH, Campo E, Harris NL. WHO classification of tumors of haematopoietic and lymphoid tissues. Revised 4th ed. Lyon: International Agency for Research on Cancer (IARC); 2017.

14. Liu L, Yang L, Yan W, Zhai J, Pizzo DP, Chu P, et al. Chemotherapy induces breast cancer stemness in association with dysregulated monocytosis. Clin Cancer Res. 2018;24(10):2370 82. https://doi.org/10.1158/1078-0432.Ccr-17-2545.

15. Bearman RM, Kjeldsberg CR, Pangalis GA, Rappaport H. Chronic monocytic leukemia in adults. Cancer. 1981;48(10):2239-55. https://doi.org/10.1002/1097-0142(19811115)48:10<2239::aidcncr2820481020>3.0.co;2-x.

16. Liebetrau C, Hoffmann J, Dörr O, Gaede L, Blumenstein J, Biermann $\mathrm{H}$, et al. Release kinetics of inflammatory biomarkers in a clinical model of acute myocardial infarction. Circ Res. 2015;116(5):867-75. https://doi.org/10.1161/circresaha.116. 304653.

17. Shin YO, Lee JB. Leukocyte chemotactic cytokine and leukocyte subset responses during ultra-marathon running. Cytokine. 2013;61(2):364-9. https://doi.org/10.1016/j.cyto.2012.11.019.

18. Hensel M, Grädel L, Kutz A, Haubitz S, Huber A, Mueller B, et al. Peripheral monocytosis as a predictive factor for adverse outcome in the emergency department: survey based on a register study. Medicine (Baltimore). 2017;96(28):e7404. https://doi.org/10. 1097/md.0000000000007404.

19. Raffray L, Giry C, Vandroux D, Fayeulle S, Moiton MP, Gerber A, et al. The monocytosis during human leptospirosis is associated with modest immune cell activation states. Med Microbiol Immunol. 2019;208(5):667-78. https://doi.org/10.1007/s00430018-0575-9.

20. Whitelock-Jones L, Carswell J, Rasmussen KC. Listeria pneumonia. A case report. S Afr Med J. 1989;75(4):188-9.

21. Silvin A, Chapuis N, Dunsmore G, Goubet AG, Dubuisson A, Derosa L, et al. Elevated calprotectin and abnormal myeloid cell subsets discriminate severe from mild COVID-19. Cell. 2020;182(6):1401-18.e18. https://doi.org/10.1016/j.cell.2020.08. 002.

22. Schulte-Schrepping J, Reusch N, Paclik D, Baßler K, Schlickeiser S, Zhang B, et al. Severe COVID-19 is marked by a dysregulated myeloid cell compartment. Cell. 2020;182(6):1419-40.e23. https:// doi.org/10.1016/j.cell.2020.08.001.

23. Karayalcin G, Khanijou A, Kim KY, Aballi AJ, Lanzkowsky P. Monocytosis in congenital syphilis. Am J Dis Child. 1977;131(7): 782-3. https://doi.org/10.1001/archpedi.1977.02120200064013.

24. Tsolia M, Drakonaki S, Messaritaki A, Farmakakis T, Kostaki M, Tsapra $\mathrm{H}$, et al. Clinical features, complications and treatment outcome of childhood brucellosis in central Greece. J Infect. 2002;44(4):257-62. https://doi.org/10.1053/jinf.2002.1000.

25. Abdalla SH. Peripheral blood and bone marrow leucocytes in Gambian children with malaria: numerical changes and evaluation of phagocytosis. Ann Trop Paediatr. 1988;8(4):250-8. https://doi. org/10.1080/02724936.1988.11748582.

26. Slavin RE, Walsh TJ, Pollack AD. Late generalized tuberculosis: a clinical pathologic analysis and comparison of 100 cases in the preantibiotic and antibiotic eras. Medicine (Baltimore). 1980;59(5):352-66. 
27. Kawakami A, Fukunaga T, Usui M, Asaoka H, Noda M, Nakajima $\mathrm{T}$, et al. Visceral leishmaniasis misdiagnosed as malignant lymphoma. Intern Med. 1996;35(6):502-6. https://doi.org/10.2169/ internalmedicine.35.502.

28. Dalugama C, Gawarammana IB. Rare presentation of rickettsial infection as purpura fulminans: a case report. J Med Case Rep. 2018;12(1):145. https://doi.org/10.1186/s13256-018-1672-5.

29. Jameson JL, Fauci AS, Kasper DL, Hauser SL, Longo DL, Loscalzo J. Leukocytosis and leukopenia. Harrison's Manual of Medicine, 20e. McGraw-Hill Education: New York; 2020.

30. Barker S, Scott M, Chan GT. Corticosteroids and monocytosis. N Z Med J. 2012;125(1360):76-8.

31. Thöne J, Kessler E. Monocytosis subsequent to ziprasidone treatment: a possible side effect. Prim Care Companion J Clin Psychiatry. 2007;9(6):465-6. https://doi.org/10.4088/pcc. v09n0611b.

32. Liu CZ, Persad R, Inghirami G, Sen F, Amorosi E, Goldenberg A, et al. Transient atypical monocytosis mimic acute myelomonocytic leukemia in post-chemotherapy patients receiving G-CSF: report of two cases. Clin Lab Haematol. 2004;26(5):359-62. https://doi.org/ 10.1111/j.1365-2257.2004.00628.x.

33. Rotman M, Ansley H, Rogow L, Stowe S. Monocytosis: a new observation during radiotherapy. Int J Radiat Oncol Biol Phys. 1977;2(1-2):117-21. https://doi.org/10.1016/0360-3016(77) 90016-5.

34. de Planque MM, Brand A, Kluin-Nelemans HC, Eernisse JG, van der Burgh F, Natarajan AT, et al. Haematopoietic and immunologic abnormalities in severe aplastic anaemia patients treated with antithymocyte globulin. Br J Haematol. 1989;71(3):421-30. https:// doi.org/10.1111/j.1365-2141.1989.tb04301.x.

35. Walter RB, Othus M, Burnett AK, Löwenberg B, Kantarjian HM, Ossenkoppele GJ, et al. Significance of FAB subclassification of "acute myeloid leukemia, NOS" in the 2008 WHO classification: analysis of 5848 newly diagnosed patients. Blood. 2013;121(13): 2424-31. https://doi.org/10.1182/blood-2012-10-462440.

36. Patnaik MM, Tefferi A. Chronic myelomonocytic leukemia: 2018 update on diagnosis, risk stratification and management. Am J Hematol. 2018;93(6):824-40. https://doi.org/10.1002/ajh.25104.

37. Mangaonkar AA, Patnaik MM. Advances in chronic myelomonocytic leukemia and future prospects: lessons learned from precision genomics. Adv Cell Gene Ther. 2019;2(2). https://doi.org/10.1002/acg2.48.

38. Yoshimi A, Lin KT, Wiseman DH, Rahman MA, Pastore A, Wang $\mathrm{B}$, et al. Coordinated alterations in RNA splicing and epigenetic regulation drive leukaemogenesis. Nature. 2019;574(7777):273-7. https://doi.org/10.1038/s41586-019-1618-0.

39. Kunimoto H, Meydan C, Nazir A, Whitfield J, Shank K, Rapaport $\mathrm{F}$, et al. Cooperative epigenetic remodeling by TET2 loss and NRAS mutation drives myeloid transformation and MEK inhibitor sensitivity. Cancer Cell. 2018;33(1):44-59.e8. https://doi.org/10. 1016/j.ccell.2017.11.012.

40. Padron E, Painter JS, Kunigal S, Mailloux AW, McGraw K, McDaniel JM, et al. GM-CSF-dependent pSTAT5 sensitivity is a feature with therapeutic potential in chronic myelomonocytic leukemia. Blood. 2013;121(25):5068-77. https://doi.org/10.1182/ blood-2012-10-460170.

41. Patnaik MM, Sallman DA, Mangaonkar AA, Heuer R, Hirvela J, Zblewski D, et al. Phase 1 study of lenzilumab, a recombinant antihuman GM-CSF antibody, for chronic myelomonocytic leukemia. Blood. 2020;136(7):909-13. https://doi.org/10.1182/blood. 2019004352.

42. Emanuel PD, Bates LJ, Castleberry RP, Gualtieri RJ, Zuckerman KS. Selective hypersensitivity to granulocyte-macrophage colonystimulating factor by juvenile chronic myeloid leukemia hematopoietic progenitors. Blood. 1991;77(5):925-9.
43. Selimoglu-Buet D, Badaoui B, Benayoun E, Toma A, Fenaux P, Quesnel B, et al. Accumulation of classical monocytes defines a subgroup of MDS that frequently evolves into CMML. Blood. 2017;130(6):832-5. https://doi.org/10.1182/blood-2017-04-779579.

44. Geyer JT, Tam W, Liu Y-C, Chen Z, Wang SA, Bueso-Ramos C, et al. Oligomonocytic chronic myelomonocytic leukemia (chronic myelomonocytic leukemia without absolute monocytosis) displays a similar clinicopathologic and mutational profile to classical chronic myelomonocytic leukemia. Mod Pathol. 2017;30(9):1213-22. https://doi.org/10.1038/modpathol.2017.45.

45.• Valent P, Orazi A, Savona MR, Patnaik MM, Onida F, van de Loosdrecht AA, et al. Proposed diagnostic criteria for classical chronic myelomonocytic leukemia (CMML), CMML variants and pre-CMML conditions. Haematologica. 2019;104(10):193549. https://doi.org/10.3324/haematol.2019.222059. This is a paper on classification and diagnosis of CMML.

46.• Selimoglu-Buet D, Wagner-Ballon O, Saada V, Bardet V, Itzykson $\mathrm{R}$, Bencheikh L, et al. Characteristic repartition of monocyte subsets as a diagnostic signature of chronic myelomonocytic leukemia. Blood. 2015;125(23):3618-26. https://doi.org/10.1182/blood2015-01-620781. This is an important study on monocyte repartioning in CMML.

47. Patnaik MM, Timm MM, Vallapureddy R, Lasho TL, Ketterling RP, Gangat N, et al. Flow cytometry based monocyte subset analysis accurately distinguishes chronic myelomonocytic leukemia from myeloproliferative neoplasms with associated monocytosis. Blood Cancer J. 2017;7(7):e584. https://doi.org/10.1038/bcj.2017. 66.

48. Feng R, Bhatt VR, Fu K, Pirruccello S, Yuan J. Application of immunophenotypic analysis in distinguishing chronic myelomonocytic leukemia from reactive monocytosis. Cytometry B Clin Cytom. 2018;94(6):901-9. https://doi.org/10.1002/cyto.b. 21721.

49. Hudson CA, Burack WR, Leary PC, Bennett JM. Clinical utility of classical and nonclassical monocyte percentage in the diagnosis of chronic myelomonocytic leukemia. Am J Clin Pathol. 2018;150(4): 293-302. https://doi.org/10.1093/ajcp/aqy054.

50. Pophali PA, Timm MM, Mangaonkar AA, Shi M, Reichard K, Tefferi A, et al. Practical limitations of monocyte subset repartitioning by multiparametric flow cytometry in chronic myelomonocytic leukemia. Blood Cancer J. 2019;9(9):65. https:// doi.org/10.1038/s41408-019-0231-7.

51. Murali A, Cross D, Mollee P. The use of monocyte subset repartitioning by flow cytometry for diagnosis of chronic myelomonocytic leukaemia. Blood Cancer J. 2021;11(1):6. https://doi.org/10.1038/s41408-020-00401-3.

52. Mangaonkar AA, Reichard KK, Binder M, Coltro G, Lasho TL, Carr RM, et al. Bone marrow dendritic cell aggregates associate with systemic immune dysregulation in chronic myelomonocytic leukemia. Blood Adv. 2020;4(21):5425-30. https://doi.org/10. 1182/bloodadvances.2020002415. This is an important paper describing for the first time, the use of CyTOF in CMML.

53. Thomas GD, Hamers AAJ, Nakao C, Marcovecchio P, Taylor AM, McSkimming C, et al. Human blood monocyte subsets: a new gating strategy defined using cell surface markers identified by mass cytometry. Arterioscler Thromb Vasc Biol. 2017;37(8): 1548-58. https://doi.org/10.1161/atvbaha.117.309145. This is an important study providing evidence that novel markers can be used to better differentiate monocyte subsets.

54. Ong SM, Teng K, Newell E, Chen H, Chen J, Loy T, et al. A Novel, Five-marker alternative to CD16-CD14 gating to identify the three human monocyte subsets. Front Immunol. 2019;10:1761. https:// doi.org/10.3389/fimmu.2019.01761.

55. Swerdlow SHCE, Harris NL, Jaffe ES, Pileri SA, Stein H, Thiele J, et al. WHO classification of tumours of haematopoietic and lymphoid tissues; 2018. p. 82-6. 
56. Grignano E, Mekinian A, Braun T, Liozon E, Hamidou M, Decaux $\mathrm{O}$, et al. Autoimmune and inflammatory diseases associated with chronic myelomonocytic leukemia: a series of 26 cases and literature review. Leuk Res. 2016;47:136-41. https://doi.org/10.1016/j. leukres.2016.05.013.

57. Mekinian A, Grignano E, Braun T, Decaux O, Liozon E, Costedoat-Chalumeau N, et al. Systemic inflammatory and autoimmune manifestations associated with myelodysplastic syndromes and chronic myelomonocytic leukaemia: a French multicentre retrospective study. Rheumatology (Oxford). 2016;55(2):291-300. https://doi.org/10.1093/rheumatology/ kev294.

Publisher's Note Springer Nature remains neutral with regard to jurisdictional claims in published maps and institutional affiliations. 